\title{
О состоянии и развитии системы мониторинга инженерных конструкций башни «Эволюция»
}
А.М.Белостоцкий, НИЦ СтаДи0, Москва
П.А.Акимов, РААСН, НИЦ СтаДи0, Москва
Т.Б.Кайтуков, РААСН, Москва
Н.0.Петрашев, НИЦ «Строительство», Москва
С.0.Петряшев, НИЦ «Строительство», Москва

Настоящая статья посвящена текущему и перспективному состоянию системы мониторинга инженерных конструкций (СМИК) башни «Эволюция» Московского международного делового центра (ММДЦ) «Москва-Сити». Данный объект выполнен в форме закрученного вокруг собственной оси 255-метрового 54-этажного небоскрёба, расположенного на трёхуровневом стилобате. В статье представлены результаты анализа научнометодической, проектной и исполнительной документации по объекту, проведён анализ действующей системы мониторинга инженерных конструкций (СМИК). В частности, приведены сведения о СМИК в части несущих конструкций, о контрольноизмерительной аппаратуре высотного здания, о действующей системе мониторинга несущих конструкций, о критериях оценки технического состояния несущих конструкций, о фасадных конструкциях, о результатах анализа достоверности объёма контролируемых параметров, оперативности и достоверности (точности и надежности) смонтированной МИК. Далее на основе изложенного даются обоснованные рекомендации по дополнению системы мониторинга в части пространственнокоординатного мониторинга с помощью ГЛОНACC/GPS-датчиков, а также контроля за фасадными конструкциями (предложения в части контрольных параметров для светопрозрачных фасадных систем, оборудования для мониторинга фасадных систем). В завершении сформулированы рекомендации по разработке и интеграции адаптивных конечноэлементных моделей несущих и фасадных конструкций. Даются необходимые ссылки на публикации авторов, посвящённые разработанной оригинальной расчётно-экспериментальной методике динамического мониторинга несущих конструкций высотных зданий. В основе этой методики лежит построение и последующее использование параметризируемых конечноэлементных моделей, адаптация (калибровка) этих моделей по данным инструментальных наблюдений с целью адекватной оценки несущей способности для фактического состояния и планирования измерений по результатам мониторинга.

Ключевые слова: математическое моделирование, численное моделирование, компьютерное моделирование, численные методы, метод конечных элементов, механическая безопасность, напряжённо-деформированное состояние, адаптивные конечноэлементные модели, система мониторинга инженерных конструкций, башня «Эволюция».
On the State and Development of Structural Health Monitoring System of the "Evolution" Tower

A.M.Belostotsky, SRC StaDy0, Moscow

P.A.Akimov, RAACS, SRC StaDy0, Moscow

T.B.Kaytukov, RAACS, Moscow

N.O.Petryashev, Research Center of Construction, Moscow S.0.Petryashev, Research Center of Construction, Moscow

The distinctive paper is devoted to the current and futureoriented state of structural health monitoring (SHM) system of the "Evolution" tower of the Moscow International Business Center (MIBC) "Moscow City". This object is made 54-story skyscraper with a height of 255 meters, twisted around its own axis, located on a three-level stylobate. The paper presents the results of the analysis of scientific, methodological, design and executive documentation for this building and analysis of the current state of the SHM system. In particular, information is given on the SHM system regarding load-bearing structures, control and measuring equipment of a high-rise building, criteria for assessments of technical condition of load-bearing structures, facade structures, results of the analysis of the reliability of monitored parameters, efficiency (accuracy) and the reliability of the mounted SHM system. Then substantiated recommendations for modification of this SHM system are provided. Corresponding recommendations deal with spatial coordinate monitoring using GLONASS/GPS sensors and monitoring of facade structures (control parameters for translucent facade systems; equipment for monitoring facade systems). Besides, recommendations for the development and integration of adaptive finite element models of load bearing and facade structures are provided. The necessary links are given to the authors' papers devoted to developed computational and experimental methodology of structural health monitoring dealing with load-bearing structures of unique buildings in terms of formulation of original basic theoretical foundations of advanced methodology of structural health monitoring, parameterized finite element models of buildings ("design" and "monitoring oriented" models), adaptation (calibration) of finite element models in accordance with results of measurements, structural evaluation in the real situation.

Keywords: mathematical modelling, numerical modelling, computer modelling, numerical methods, finite element method, 
mechanical safety, stress-strain state, adaptive finite element models, structural health monitoring, "Evolution" tower.

\section{1. Постановка задач и исходная информация}

\section{1. Описание конструкции и каркаса}

\section{многофункционального комплекса}

В основе архитектурной концепции башни «Эволюция» лежит идея статичного центрального ядра с сеткой колонн и вращающегося вокруг них фасада (рис. 1) [1; 2]. Уникальный визуальный эффект достигается путём поворота каждого последующего этажа относительно предыдущего примерно на $3^{\circ}$, что составляет в общей сложности $135^{\circ}$. Техническими этажами являются 12-ый, 29-ый, 46-ой и 51-ый. Высота здания без венчающей его верх «короны» составляет 233,2 метра над уровнем земли. Конструкция указанной «короны» формирует художественный элемент на вершине башни.

Фундамент здания - бетонная плита размерами 51,55×52,55 м, толщиной 3,5 м, опирающаяся на сваи диаметром 1,5 м. В подземной части здания имеются два этажа высотой 3,45 м каждый и этаж высотой 4,70 м. Цокольный этаж расположен на 0,25 м ниже уровня земли. Надземная часть здания имеет примерные размеры в плане 42,65×43,65 м. Вертикальное расстояние между перекрытиями надземной части здания за некоторыми исключениями составляет 4,3 м. 3дание было возведено из монолитного железобетона, опирается на свайно-плитный фундамент, который деформационным швом отрезан от плитного фундамента подиума.

Несущий каркас объекта состоит из центрального ядра жёсткости с изменяющейся толщиной стен, восьми круглых внутренних колонн и четырёх колонн прямоугольного сечения, расположенных по углам здания. По всей высоте здания положение центрального ядра и внутренних колонн остаётся неизменным. Наружные же колонны следуют «закручиванию» башни. Центральное ядро и внутренние колонны уменьшаются в размерах по мере увеличения высоты здания. С отметки верха фундаментной плиты до верха здания толщина стен снижается с 800 до 400 мм. По наружным углам здания расположены колонны прямоугольного поперечного сечения, которое также уменьшается по высоте (с $1500 \times 1500$ мм до $1000 \times 1500$ мм). Диаметр внутренних колонн круглого поперечного сечения также постепенно уменьшается по мере увеличения высоты здания (с 2100 мм до 1200 мм). Все колонны за некоторым исключением выполнены из бетона класса В80. Для всех этажей за некоторым исключением по наружным колоннам расположены балки сечением $1200 \times 550$ мм, на внутренних колоннах расположены широкие балки сечением $2400 \times 550$ мм, между балками расположена плита перекрытия, толщиной 310 мм, а в зоне ядра - 550 мм. В качестве материала для балок и перекрытий использовался бетон класса В60, материал фундаментной плиты - бетон класса В45, сваи выполнялись из бетона класса В50. Под концами свай производилась цементация известняков на глубину около 6 м.

\section{2. Грунтовые условия и свайное поле}

Рельеф площадки строительства относительно ровный, полностью антропогенный, сформированный на толще насыпных грунтов. На основании результатов соответствующих инженерно-геологических изысканий, выполненных на площадке, был сделан вывод о сложности инженерно-геологических условий подземного пространства. В соответствии с конструктивной схемой здания и грунтовыми условиями была принята конструкция свайно-плитного фундамента, при этом использовались буронабивные сваи диаметром 1500 мм. В целях выравнивания осадок ростверка (и, как следствие, - уменьшения изгибающих моментов в колоннах и стенах) сваи по полю плиты были распределены следующим образом: под наиболее нагруженными стенами и колоннами были устроены кусты буронабивных свай диаметром 1500 мм с шагом $3000 \times 3000$ мм. В местах, где нагрузки относительно небольшие, шаг свай был разрежен. Для обеспечения общей устойчивости здания и исключения значительных кренов лестнично-лифтовых блоков плитный ростверк был принят неразрезным без деформационных швов в пределах всей подземной части здания. Толщина плитного ростверка была принята равной 3500 мм в зоне основных несущих элементов и 2500 мм по периметру. Заметим, что в основании плитного ростверка залегают глины мергелистые с прослоями мергеля полутвёрдой консистенции.

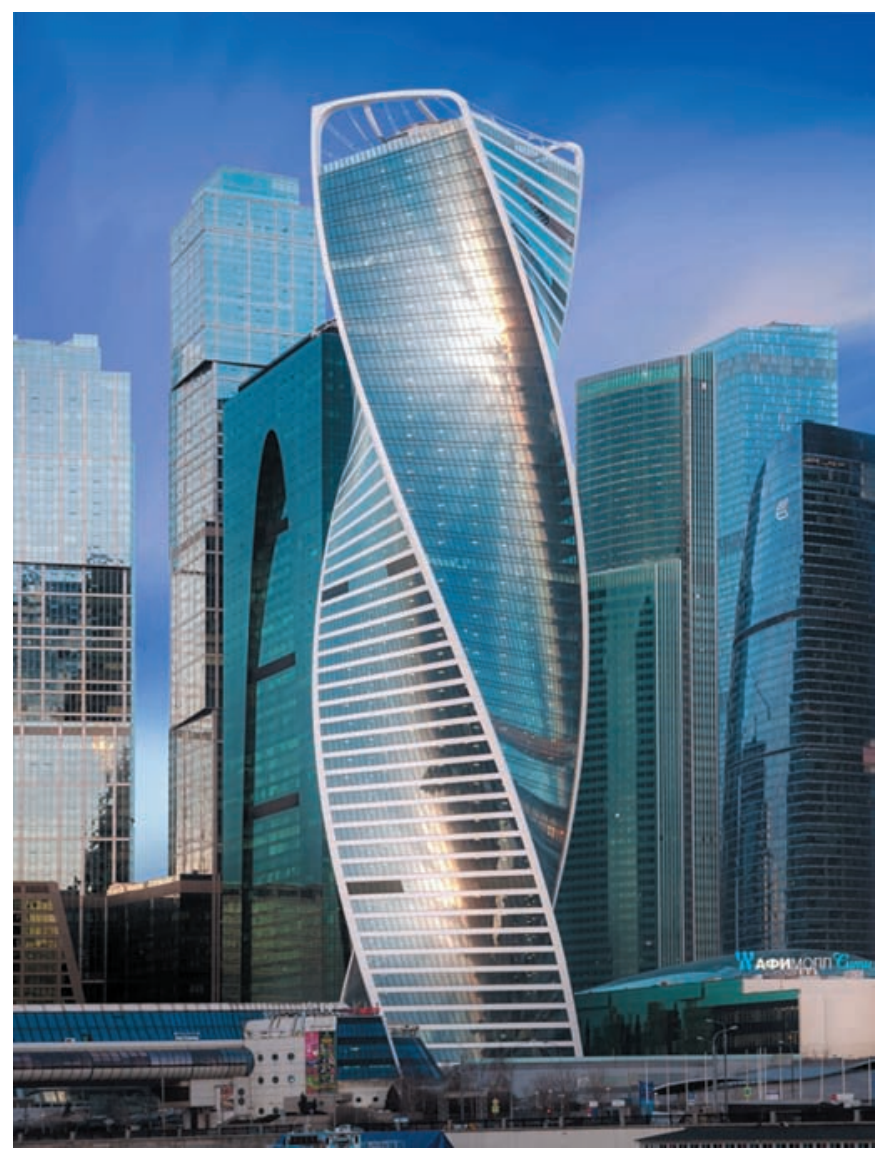

Рис. 1. Внешний вид башни «Эволюция» 


\section{3. Замеры отклонений колонн и стен от проекта}

В рамках мониторинга качества работ по возведению здания были выполнены следующие виды работ: создание планово-высотной опорной геодезической сети; выполнение исполнительной съёмки отклонений стен и колонн от проектных положений; выполнение исполнительной съёмки отклонений уровня перекрытий и балок от горизонта; выполнение исполнительной съёмки фактических габаритов. Данные по измеренным отклонениям стен и колонн от проектного положения должны были быть учтены в качестве исходных данных при актуализации математической модели с точки зрения перспективы её интеграции в действующую СМИК.

\section{2. Анализ действовавшей (на момент проведения исследований) Смик}

\section{1. СМИК в части несущих конструкций}

По результатам сопоставления проекта СМИК, получившего положительное заключение Мосгорэкспертизы, и фактической [действовавшей на момент проведения исследований (2016 год)] СМИК было указано на следующие основные отличия:

- была скорректирована этажность объекта (проект СМИК был разработан для 48-этажного здания);

- отсутствовали комплект GPS, датчики-измерители относительных осадок, тензометрические датчики [согласно проекту в СМИК должны были входить следующие датчики: инклинометры (наклонометры), акселерометры, датчики деформаций железобетона, комплект GPS, датчики измерители относительных осадок, тензометрические датчики];

- в соответствии с проектом измерения перемещений верха здания должны были осуществляться с применением высокоточных GPS-приёмников, однако информация об их фактическом использовании отсутствовала;

- отсутствовали сведения о наличии и расположении приёмника GPS и антенны GPS;

- не соответствовала частота установки измерительного оборудования выше 36-го этажа [соответствующим проектом предусматривалось размещение измерительного оборудования на одиннадцати уровнях, соответствующих этажам с номерами -3, 2, 6, 11, 16, 21, 26, 31, 36, 41, 46 (каждый пятый этаж); фактически измерительное оборудование установлено на десяти уровнях, соответствующих этажам с номерами -3, $0,6,11,16,21,26,31,36,51)$, в частности, отсутствует соответствующее оборудование на 41-ом и 46-ом этажах];

- отсутствовали сведения о наличии и расположении регистраторов осадок DSM и датчиков DSM (должны были быть размещены на колоннах нижнего уровня здания);

- система геотехнического мониторинга не была согласована со СМИК (информация о согласованности отсутствовала, в проекте СМИК такое согласование предусматривалось);

- схемы размещения измерительного оборудования в плане здания не соответствовали схемам, представленным в проекте;
- информация по компьютерной модели объекта, согласованной со СМИК, отсутствовала (согласно проекту должна была быть разработана адекватная компьютерная модель объекта с учётом экспериментальных данных по объекту).

Сопоставительный анализ проекта и исполнительной документации по системе мониторинга [3; 4] подземной части позволил выявить, в частности, следующее:

- с целью оценки напряжённо-деформированного состояния (НДС) фундамента высотного здания проектом было предусмотрено установить преобразователи давления плиты на сваю типа ГД-10 в соответствующие сваи, однако по факту указанные преобразователи не были установлены в сваи, определённые проектом; контрольно-измерительная аппаратура для определения напряжений в арматуре и для определения деформаций бетона была установлена не в определённых проектом сваях, а в других;

- по факту было установлено три единицы датчиков ГД-10 в стяжке фундаментной плиты вместо восьми, предусмотренных проектом преобразователей давления на грунт типа ГД-10; преобразователи давления воды типа ПДС-ЗП под фундаментной плитой не были установлены (проектом их было предусмотрено восемь); для определения деформаций бетона фундаментной плиты проектом была предусмотрена установка 16-ти датчиков ПЛДС-400 для определения деформаций, однако фактически указанные датчики установлены не были; в проекте не было информации, но по факту в трёх точках фундаментной плиты на вертикальной арматуре было установлено 12 датчиков ПСАС-28;

- в проекте не было информации по установке в несущих колоннах датчиков ПСАС-28С (16 штук) и датчиков ПЛДС-400 (8 штук) (для оценки нагрузки и её изменения в несущих колоннах здания в восьми из них по факту были установлены указанные датчики).

\section{2. Контрольно-измерительная аппаратура высотного} здания

Контрольно-измерительная аппаратура (КИА) высотного здания включала следующие составляющие:

- ПСАС-28 - преобразователи силы арматурные струнные, предназначенные для определения напряжений в арматуре (рис. 2 a);

- ПлДС-400 - преобразователи линейных деформаций струнные, предназначенные дли определения деформаций бетона (рис. 2 б);

- ПТС-60 - преобразователи температуры, предназначенные для определения температуры в элементах конструкций (рис. 2 в);

- ИН-ДЗц 720 - измерители наклона двухкоординатные цифровые, предназначенные для определения малых углов наклона и наклонных перемещений консольных частей здания (рис. 2 г);

- ГД-10 - грунтовый динамометр, предназначенный для определения давления на грунте (рис. 2 д); 
- A1638 - сейсмоприемники (акселерометр) пьезоэлектрические (рис. 2 е);

- LTR114 - система сбора данных, предназначенная для сбора данных с датчиков вибрации (акселерометров) (рис. 2 ж);

- КИД-С - комплекс измерения деформаций стержневой для измерения перемещений и деформаций растяжения (сжатия) элементов конструкции (рис. 2 3);

- многоканальный программируемый терминал (МПТ) - ядро современных систем автоматизированного сбора информации.

\section{3. Действующая система мониторинга несущих конструкций}

Вообще мониторинг базируется на применении методов неразрушающего контроля элементов фундамента здания путём измерения напряжённого состояния и перемещений элементов фундамента конструкций, возникающих в ходе строительства и эксплуатации здания, что позволяет контролировать величину и изменение деформаций конструктивных элементов.

Проект мониторинга подземной части содержал следующие типы датчиков:

- грунтовый динамометр ГД-10 (три штуки в стяжке фундаментной плиты), предназначенный для определения давления на грунт;

- преобразователи силы арматурные струнные ПСАС-28Р (16 штук в одной из сеток фундаментной плиты), предназначенные для определения напряжений в арматуре;

- преобразователи силы арматурные струнные ПСАС-28 (12 штук на вертикальной арматуре фундаментной плиты в районе некоторых свай), предназначенные для определения напряжений в арматуре;

- преобразователи силы арматурные струнные ПСАС-28С [16 штук в арматуре одной из сеток верхней части плиты; 16 штук - в некоторых несущих колоннах -3-го этажа; 24 штуки, по одному датчику в верхнем, среднем и нижнем уровне некоторых свай (частично вышли из строя к 2013 году)], предназначенные для определения напряжений в арматуре (в том числе в арматуре свай), а также для оценки нагрузки и её изменения в несущих колоннах здания;

- преобразователи температуры ПТС-60 (восемь штук в одной из сеток нижней части фундаментной плиты; восемь штук в арматуре одной из сеток верхней части плиты), предназначенные для определения температуры бетона;

- преобразователи линейных деформаций струнные ПлДС-400 [16 штук в арматуре одной из сеток верхней части плиты; восемь штук в некоторых несущих колоннах -3-го этажа; 24 штуки - по одному датчику в верхнем, среднем и нижнем уровне некоторых свай (частично вышли из строя к 2013 году)], предназначенные для определения деформаций бетона, а также для оценки нагрузки и её изменения в несущих колоннах здания и в сваях;

- наклонометр ИН-ДЗц 720 (четыре штуки на колоннах по углам фундаментной плиты), предназначенный для опреде-

ления крена фундаментной плиты в процессе строительства здания и эксплуатации.

Проект СМИК содержал следующее измерительное оборудование:

- комплект измерения деформации КИД-С (12 штук, на каждой из восьми основных колонн -3-го этажа, четыре датчика на стенах центрального ядра -3-го этажа; 16 штук - на каждой из восьми основных колонн, на каждой угловой колонне нулевого этажа, четыре датчика на стенах центрального ядра нулевого этажа; 84 штуки - на каждой из восьми основных колонн на уровне некоторых этажей, четыре датчика на стенах центрального ядра на уровне некоторых этажей; восемь штук на каждой из восьми основных колонн на уровне 51-го этажа), предназначенный для определения деформаций;

- инклинометр ИН-Д3 (24 штуки: под перекрытием некоторых этажей - по одному датчику около некоторых колонн, по одному датчику около стен на пересечении соответствующих осей), предназначенный для определения угла наклона (отклонение по вертикали по двум координатам);

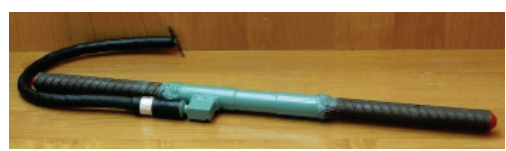

a)

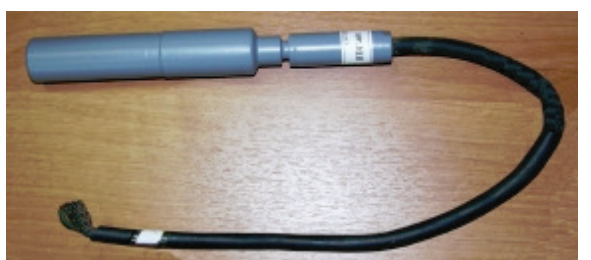

B)

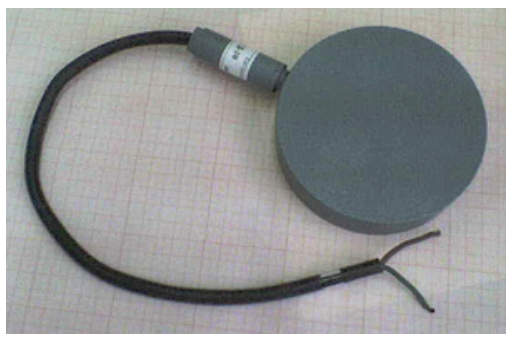

d)

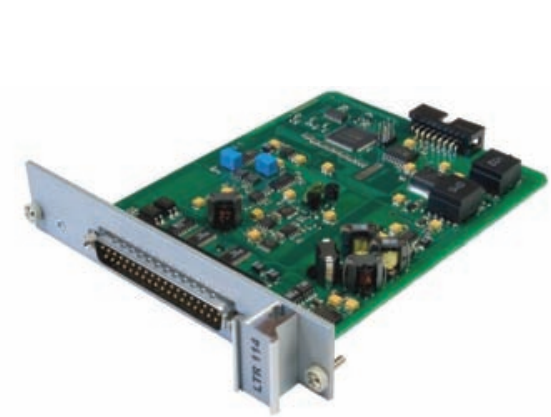

ж)

Рис. 2. Контрольно-измерительная аппаратура (КИА) высотного здания: а) ПСАС; б) ПЛДС; в) ПТС-60; г) датчик измерения наклона; д) ГД; е) A1638; ж) LTR114; з) КИД-С. 
- акселерометр (сейсмоприёмники) А1638 (шесть штук: на потолке некоторых этажей - один датчик около одной из колонн, один датчик на пересечении соответствующих осей), предназначенный для определения ускорений (косвенно перемещений).

\section{4. Критерии оценки технического состояния несущих} конструкций

В действующей СМИК отсутствовала информация по критериям оценки технического состояния несущих конструкций здания. Было отмечено, что установка датчиков и предельно допустимых контролируемых параметров были произведены в соответствии с требованиями нормативных документов .

Согласно ТР П-119-03-СМ-02-2010 [5] проект системы мониторинга деформационного состояния несущих конструкций должен был содержать обоснование и перечень контролируемых параметров НДС несущих конструкций. Параметры, требующие контроля и их расчётные (контрольные) значения, определяются на основании нормативных документов, проекта и результатов математического (компьютерного) моделирования.

\section{5. Фасадные конструкции}

В проекте системы мониторинга и в действующей СМИК полностью отсутствовала система мониторинга устройства фасадных конструкций. Согласно ТР П-119-03-СМ-02-20102, при мониторинге должен был осуществляться контроль монтажа и состояния конструкций фасадов. В процессе контроля выполняемых фасадных работ определяются надёжность, прочность крепления архитектурных и конструктивных деталей, облицовки, а также контролируется состояние металлических элементов, кронштейнов и пр. При мониторинге навесных светопрозрачных систем выборочно проверяются поверхности несущих конструкций здания (колонн, ригелей) - под устройство навесных систем (геодезическая съёмка), крепёжные элементы - на несущую способность, адгезия клеящего состава и качество очистки поверхностей несущих конструкций, несущие элементы системы, узлы крепления несущих профилей, деформационные швы, узлы примыканий, стыки светопрозрачных элементов, выполнение узлов примыкании навесных светопрозрачных систем к другим системам, применённым на здании.

\section{6. Анализ достаточности объёма контролируемых па-} раметров, оперативности и достоверности (точности и надёжности) смонтированной СмИК

В действующей СмИК был обеспечен мониторинг следующих основных параметров: изменение напряжения в арматуре ростверка; углы наклона ростверка; нагрузка и её изменения в несущих угловых и некоторых других колоннах -3-го этажа; изменение деформация (напряжений), действующих в вертикальных несущих конструкциях; углы наклона конструкций ядер и периферии зданий; амплитуды ускорений, смещения и частоты на -3-ем, 26-ом и 51-ом этажах рассматриваемого здания.

Таким образом, отсутствовал контроль параметров состояния горизонтальных конструкций, а также отсутствовал контроль параметров внешнего воздействия (ветровая нагрузка, температура), необходимый для корректного анализа изменений деформированного состояния конструкций исследуемого здания. Неполнота параметров была отражена в рекомендациях по дополнению системы мониторинга инженерных конструкций.

В целом действующая система мониторинга не обеспечивала достоверность получаемых параметров. Проектом предусматривалась установка тензометрических датчиков деформации на арматуру в процессе строительства, фактически же были установлены комплексы измерения деформаций КИД-С по завершению строительства несущих конструкций. Таким образом, это оборудование измеряло изменение напряжённого состояния конструкции после момента установки датчиков деформации. Результаты измерений углов наклона опять же носят весьма условный характер, так как измеряются отклонения с момента установки инклинометров до текущего состояния.

Оперативность обеспечивается в результате постоянного мониторинга состояния инженерных конструкций и автоматического принятия решений о критическом изменении состояния инженерных конструкций путём сравнения настроек программного комплекса мониторинга для каждого датчика и данных, получаемых в режиме реального времени. При функционировании СМИК объекта в автоматическом режиме реального времени опрос всех информационных компонентов СМИК производится не реже, чем один раз в час. Принятие решений по обеспечению безопасной эксплуатации объекта осуществляется эксплуатирующей организацией по данным автоматического (в режиме реального времени) мониторинга параметров инженерных (несущих) конструкций, поступающих операторам СМИК и серверу СМИК, или в соответствии с полученным по результатам периодического (внеочередного) мониторинга заключением о состоянии инженерных (несущих) конструкций объекта. В целом очевидно, что необходимо обеспечить точность, надёжность, достоверность и оперативность СМИК.

\section{Лumepamypa}

1. Расчётные исследования напряжённо-деформированного состояния, прочности и устойчивости несущих конструкций высотного здания с учетом фактического положения железобетонных конструкций / А.М. Белостоцкий, П.А. Акимов, Н.О. Петряшев [и др.] // Вестник МГСУ. - 2015. - № 4. - C. 50-68.

2. Strength and stability analysis of loadbearing structures of Evolution tower with allowance for actual positions of reinforced concrete structural memembers / A.M. Belostotsky, P.A. Akimov, T.B. Kaytukov [et al] // Procedia Engineering. 2016. - Vol. 153. - P. 95-102. 
3. Белостоцкий А.М. Научно-исследовательский центр СтаДи0. 25 лет на фронте численного моделирования / А.М. Белостоцкий, П.А. Акимов // International Journal for Computational Civil and Structural Engineering. - 2016. - Vol. 12, Is. 1. - P. 9-34.

4. Белостоцкий А.М. Обзорно-аналитическое исследование нормативно-методической литературы в области мониторинга зданий и сооружений / А.М. Белостоцкий, П.А. Акимов // International Journal for Computational Civil and Structural Engineering. - 2016. - Vol. 12, Is. 2. - P. 42-64.

5. Анализ результатов геотехнического мониторинга башни «Лахта Центр» / В.И. Травуш, 0.А. Шулятьев, С.0. Шулятьев, А.М. [и др.] // Основания, фундаменты и механика грунтов. - 2019. - № 2. - С. 15-21.

\section{References}

1. Belostotskii A.M., Akimov P.A., Petryashev N.0., Petryashev S.0., Negrozov 0.A. Raschetnye issledovaniya napryazhennodeformirovannogo sostoyaniya, prochnosti i ustoichivosti nesushchikh konstruktsii vysotnogo zdaniya s uchetom fakticheskogo polozheniya zhelezobetonnykh konstruktsii [Strength and stability analysis of load-bearing structures of a high-rise building with account for actual positions of reinforced concrete structural members]. Vestnik MGSU, 2015, no. 4, pp. 50-68. (In Russ).
2. Belostotsky A.M., Akimov P.A., Kaytukov T.B., Petryashev N.0., Petryashev S.0., Negrozov 0.A. Strength and stability analysis of load-bearing structures of Evolution tower with allowance for actual positions of reinforced concrete structural memembers. Procedia Engineering, 2016, Vol. 153, pp. 95-102.

3. Belostotsky A.M., Akimov P.A. Nauchno-issledovatelskiy tsentr StaDy0. 25 let na fronte chislennogo modelirovaniya [25-th Anniversary of scientific research centre StaDy0]. International Journal for Computational Civil and Structural Engineering, 2016, Vol. 12, Issue 1, pp. 9-34 (in Russ.).

4. Belostotsky A.M., Akimov P.A. Obzorno-analiticheskoye issledovaniye normativno-metodicheskoy literatury $v$ oblasti monitoringa zdaniy i sooruzheniy [Review and analysis of design codes and methodological literature in the field of structural health monitoring]. International Journal for Computational Civil and Structural Engineering, 2016, no. 2(12), pp. 42-64 (in Russ.).

5. Travush V.I., Shulyat'ev 0.A., Shulyat'ev S.0., Shakhraman'yan A.M., Kolotovichev Yu.A. Analiz rezul'tatov geotehnicheskogo monitoringa bashni "Lakhta Centr" [Analysis of the results of geotechnical monitoring of "Lakhta Center" tower]. Osnovaniya i fundamenty [Soil Mechanics and Foundation Engineering], 2019, no. 2, pp. 15-21 (in Russ.).

Белостоцкий Александр Михайлович (Москва). Доктор технических наук, профессор, член-корреспондент РААСН. Генеральный директор Научно-исследовательского центра «СтаДи0» (125124, Москва, ул. 3-я Ямского Поля, д.18, оф. 810. НИЦ «СтаДи0»). Эл.почта: amb@stadyo.ru.

Акимов Павел Алексеевич (Москва). Доктор технических наук, профессор, академик РААСН. Главный учёный секретарь Российской академии архитектуры и строительных наук (107031, Москва, ул. Большая Дмитровка, 24. РААСН), заместитель директора по науке Научно-исследовательского центра «СтаДи0». Эл.почта: akimov@raasn.ru.

Кайтуков Таймураз Батразович (Москва). Кандидат технических наук, доцент, советник РААСН. Заместитель главного учёного секретаря Российской академии архитектуры и строительных наук (107031, Москва, ул. Большая Дмитровка, 24. РААСН). Эл.почта: kaytukov@raasn.ru.

Петряшев Николай Олегович (Москва). Инженер Центрального научно-исследовательского института строительных конструкций (ЦНИИСК) им. В.А. Кучеренко АО «Научно-исследовательский центр “Строительство”» (109428, Москва, ул. 2-я Институтская, 6. ЦНИИСК им. В.А. Кучеренко).Эл.почта: petryashev.n.o@gmail.com.

Петряшев Сергей Олегович (Москва). Инженер Центрального научно-исследовательского института строительных конструкций (ЦНИИСК) им. В.А. Кучеренко АО «Научно-исследовательский центр “Строительство” (109428, Москва, ул. 2-я Институтская, 6. ЦНИИСК им. В.А. Кучеренко). Эл.почта: petsero@mail.ru.

Belostotsky Alexander Mikhailovich (Moscow). Doctor of Technical Sciences, Professor, Corresponding Member of RAACS. General Director of the Research Center "StaDi0" (18 3-ya Yamskogo Polya St., office 810, Moscow, 125124. SRC StaDy0). E-mail: amb@ stadyo.ru. 
Akimov Pavel Alekseevich (Moscow). Doctor of Technical Sciences, Professor, Full Member of the RAACS. Executive Scientific Secretary of the Russian Academy of Architecture and Construction Sciences (24 Bolshaya Dmitrovka St, Moscow, 107031, RAACS), Deputy Director for Science of the Scientific Research Center StaDy0 (18 3-ya Yamskogo Polya St., office 810, Moscow, 125124. SRC StaDy0).E-mail: akimov@raasn.ru.

Kaytukov Taymuraz Batrazovich (Moscow). Candidate of Technical Sciences, Associate Professor, Advisor of the RAACS. Deputy Executive Scientific Secretary of the Russian Academy of Architecture and Construction Sciences (24 Bolshaya Dmitrovka St, Moscow, 107031, RAACS). E-mail: kaytukov@raasn.ru.

Petryashev Nikolay Olegovich (Moscow). Engineer of the Research Institute of Building Constructions (TSNIISK) named after V.A. Koucherenko A0 "Scientific-Research Center "Construction" (6 2-ya Institutskaya St, Moscow, 109428. TSNIISK). Email: petryashev.n.o@gmail.com.

Petryashev Sergey Olegovich (Moscow). Engineer of the Research Institute of Building Constructions (TSNIISK) named after V.A. Koucherenko A0 "Scientific-Research Center "Construction" (6 2-ya Institutskaya St, Moscow, 109428. TSNIISK). E-mail: petsero@mail.ru. 